\title{
An Investigation into the Challenges and Successes of Students on the Distance Education Programme: The Case of Kwame Nkrumah University In Zambia
}

\author{
Jive Lubbungu, Vincent Mudenda \\ Department of Literature and Languages \& Department of Physical Sciences
}

\begin{abstract}
This study was aimed at investigating the challenges and successes facing open and distance learning students at Kwame Nkrumah University(KNU). The study was conducted at KNU campus in Zambia. The study employed both quantitative and qualitative approaches using a descriptive design. The results showed that content, organisational, pedagogical, communicative and personal growth competencies still haunt the Distance Education area. Furthermore, the study revealed insights into factors linked to the expectations, support of students and lecturers alike, which proved influential in terms of lecturers' output and students resilience and motivation to remain on course. The implications for teacher education are clear. The students' progression rate and their stay on the programme depends on the support provided while lecturers' motivation to deliver quality information depends on their competencies and the support they get from the managerial system. Additionally, growth in enrolments will depend on the institution's capacity to provide appropriate academic and student support and therefore assessment of programme inputs and outcomes is a crucial component of educational effectiviness.
\end{abstract}

Keywords: Content, Organisational, Pedagogical, Communicative, Personal growthcompetencies, Challenges, Successes.

\section{INTRODUCTION}

UNESCO (2002) underscores the contribution open and distance learning makes to social and economic development, as a fast becoming accepted and indispensable part of the main stream of educational systems in both developed and developing countries. It, however, highlights the challenges involved in the provision of ODL. Prominent among them include uneven distribution of resources coupled with intolerable inequalities both between and within nations.

Knowledge about common challenges and successes of students in the distance education programme at Kwame Nkrumah University in Zambia has been and should continue to be an area of concern. This is because student rentention and progression depends on the support they receive from; first the lecturers, immediate family members and thirdly their peers. In 2010 the University research committee conducted a research into this area and the findings showed a number of teething problems at the time. Issues of inadequate modules and poor distribution, inadequate lecture rooms, long ques for payments of fees, and registration, seemingly inadequate prepared lecturers, verbal harassments in some cases, poor career counselling, inadequate library resources, inadequate textbooks and many other concerns were reported. A follow up research was conducted in August 2016 which also captured the lecturers involved in teaching distance students. The results showed steady improvents in a number of areas except in the areas of poor module distribution, inadequate lecture rooms, long ques for registration, inadequate teaching and learning materials, poor writing and research skills by students,limited time for residential school and much else.

The earlier report was followed by a number of transformations and some successes were scored which we are all witnesses today. It is common knowledge that we should all: enhance the sense of belonging to our Distance Students; use social networking tools such as Facebook to help social and academic integration (although this tool should not be abused); support strong interpersonal relationship between students; work closely with students to identify how they can support each other to prosper and succeed at university ; reduce factors that make students doubt; and increase factors that make students want to stay. 


\section{REVIEW OF LITERATURE}

Diffferent scholars have carried out researches on distance education and have documented the challenges and successes of this kind of education provision. Among them are Maxwell,C.C. Musigafi et al (2015) who investigated the challenges facing Open and Distance learning students at the Zimbabwe Open University (ZOU). The results showed that ODL learners were challenged with a range of obstacles in their course of studies. The most reported challenges were lack of sufficient time for study, difficulties in access and use of ICT, ineffective feedback and lack of study materials.For instance, students were unhappy with delayed feedback on their performance. As reported by Hara and Kling (2001) students experience confusion, anxiety, and frustration due to lack of prompt or clear feedback from their lecturers. Thus, delayed and ineffective feedback can add burden to learners who are struggling with the isolation and the remoteness nature of distance learning (P.63).

Most respondents in Maxwell's research at Zimbabwe Open University were adults who were selffinancing their studies. With a host of other obligations back home finance became an automatic hurdle. The results further indicate that Several respondents have postponed semesters and examinations at least once due to other commitments, especially children school fees. Furtherstill, about $40 \%$ reported lack of support from employers as a challenge facing them. He reports that a follow up discussion revealed that students were denied permission to attend examinations. Maxwell argues that the fact that the students persisted even under this unfriendly environment is a clear indication that they were highly committed to advancement of their education. Hence, this was a clear indication of motivation in learning.

Another related observation was that of lost assignments and test scripts. A follow up engagement with respondents showed that the problem of scripts getting lost frustrated, discouraged and brought many discomforts to students. Meanwhile the issue of delayed study materials especially modules made students unhappy. Most of the respondents (95\%) received study materials late or never got them. In this situation, as reported by Maxwell, C. et al (2015), students are affected academically, psychologically, and financially. Lack of study materials may force students to submit sub-standard assignments and are most likely to get to examinations without enough preparation resulting in poor performance.

Berge et al (2002) as cited by Maxwell, C. Et al (2015) classified challenges to distance learners as situational, espistemological, philosophical, pedagogical, technical, social, and /or cultural related challenges while Zirnke (2001) indentified specific challenges facing distance learners as programme costs, lack of equipment and infrastructure, instructional concerns and poor technical assistance. Other challenges documented by Zirke are inadequate feedback and poor teacher contact, alienation and isolation, and poor student support services.

Garland (2007) indentified some situational challenges for students to be persistence in distance learning. These include poor learning environment and lack of time. For instance, stuudents felt that the course took more time than anticipated because they failed to judge the demands of work, home and school. Kimber (1989) as cited by Maxwell et al (2015) argued that poor time management leads to challenges such as learners's inability to integrate the demands of off campus study with family, work and social commitments.

Samuel Nsiah Agyemang (2006) catalogues the issues that characterize distance education system in relation to access, quality, equity and relevance face the students at University of Ghana thus:

- Inadequate infrastructure and info-structure ( poor infrastructure, inadequate classrooms, teaching aids, and poor learning environments due to neglect of the physical facilities at the various centers in Ghana).

- Lack of adequate staff development programmes for sustainable career structure.

- Inadequate instructional materials, books and learning materials

- Gender disparity which is more pronounced in the rural areas

- Declining standards in quality with learner achievement test results comparing, unfortunately with other countries in the region.

- Lack of funding from the government 
An Investigation into the Challenges and Successes of Students on the Distance Education Programme: The Case of Kwame Nkrumah University in Zambia

- Lack of effective monitoring of the management

- Inadequate directional, relevant and functional curriculum

- Inadequate teaching and learning facilities leading to pooly prepared students and lack of self confidence in student graduates.

- Lack of correct and reliable operational data and statistics for education planning

- Inadequate administrative procedures

- And lack of systematic approach in ICT use in distance education settings in order to tap into the potential of ICTs to address the challenges in the distance education system.

Samuel submits that these challenges have resulted from different political systems, population growth, international and national decrees and a new socio-economic dispensation while Prof. Swaraj Basu (2012) argues that the main challenge of distance learning is that direct real-time feedback from the students or teachers is not possible.

Ukpo (2005) found that teachers who enrolled in the ODL face challenges related to failure of trainees to receive training materials on time, students' engagement in other economic activities to supplement their family incomes, and poor learner support services especially where study centres are under resourced and overstretched. Kamau (2007) found that, without an effective learner support service system that provides on-site face to face, timely feedback on student performance and access to library services, student achievement will be undermined and dropout rates and proclastination will increase.

ODL also presents new challenges in information dissemination, especially in developing countries. Mossberger et al (2003) observes that technical competence needed in order to have effective access to contemporary ICT is a challenge to distance learners. Technical competence refers to the skills needed to operate the hardware and software of ICT, including the skills of using network systems to access and share information (Warschauner, 2003). Lack of these skills is a critical challenge as learner may fail to use the various physical, digital and human resources involved in ICT.

These challenges, according to Maxwell, C. et al (2015), prompt many problems in distance learning. Among these problems are high rate of students' dropout and late programme completion. According to Carr (2000), in the US dropout rates range from 20\% to 50\%. The OECD (2000) reported that dropout rates range from $20 \%$ in the United Kingdom to $45 \%$ or more in Austria, France, and Portugal. In Australia, dropout rates range from 35\% to over 55\% (Fozdar et al, 2006). In African countries the drop-out rate is estimated to be over $50 \%$ (Daniel).

\section{Statement of Purpose}

This study sought to investigate the challenges and successes facing students of ODL and lecturers involved in teaching ODL students using Kwame Nkrumah University as a case study. Many ways could have been used but for this case an evaluation of their two-week stay, by looking at their interactions with peers, lecturers, administrators of the programme as well as lecturers and course materials seemed feasible alternative for the researcher.

\section{Significance OF THE STUdY}

The findings could be used as a basis for better organized (with large sample size) researches on various issues that affect Distance Educattion at Kwame Nkrumah University in Zambia. Gained insights into good practices could be used as a base to reinforce the programme.It is also hoped that the results of the investigation will trigger a debate on how best all the stakeholders especially the academic staff can participate positively to improve and sustain student progression. And finally, we will discover what interventions are needed through education, training and management.

\section{Research Methods and Study Participants}

There were no special tools used to select students and lecturers alike. Participants were simply picked at random across combinations and year of study and didfferent departments for lecturers. Since the researcher's interest was to simply hear their views all students and lecturers were taken as having the potential to offer the most powerful insights into their challenges, successes and into ways 
in which they had felt motivated to progress. The study adopted a mixed methods approach involving both quantitative and qualitative data collection methods using a descriptive design. This combination of quantitative and qualitative approaches complemented each other and allowed complete analysis. Questionnaires and unstructured interviews were used for data collection with a simple random sample of 115 (out of 202 questionnaires that were given out).

\section{RESUlTS AND DiscuSSION}

\subsection{Content Competencies}

$68 \%$ of the respondents were dissatisfied with their course lecturer's content competencies. They indicated that there was a visible struggle to lecture or lead a tutorial from their own module. Their expectations of what it means to be a university student in relation to content coverage were unsatisfactory. However, $21 \%$ of the participants were impressed with their lecturers' content delivery and coverage on the modules. $11 \%$ remained mute on lecturers' content competencies. A follow up engagement with students in August 2016 revealed a remarkable improvements on lecturers' content competencies as $73 \%$ of the respondents were satisfied with their lectuerers' content delivery and coverage. $19 \%$ of the participants were dissatisfied with lecturer's content competencies while $8 \%$ were not sure of lecturer's content competencies.

Incompetence in content emerged within this research as being one of the main reasons that students felt that their progress had been impeded. Some respondents said their lecturers were good at setting very hard questions which they, lecturers, were failing to explain. They also appeared to contribute to loss of confidence. Perhaps the incopentence aspect being highly rated among the respodents is justifed because the University was in its infancy in its transformation from a college to a University. Hence, there were a lot of teething problems that came with its transformation. Any wonder, five years down the line we had $73 \%$ of the respodents commending lecturer's content competencies.

\subsection{Pedagogical Approaches}

$52 \%$ of the respondents of the students were happy with the pedagogical approaches lecturers were employing. $41 \%$ were dissatisfied with the pedagogical approaches. They pointed out that lecturers failed to create a stimulating learning environment. Furthermore, some lecturers failed to link different situations with appropriate pedagogical insights. $7 \%$ did not rate their lecturers on pedagogical competencies. However, a follow up reseach in August 2016 showed an increase in percentage of respondents who were happy with lecturers pedagogical approaches (66\%). $28 \%$ were dissatisfied while 6\% remained undecided. This improvement on lecturers' pedagogical approaches could be as a result of Quality Assurance workshops and human resources development programmes the university embarked on as early as 2013.

\subsection{Peer Teaching}

$97 \%$ of the repondents were happy with team/(group) teaching considering the large number of students. 3\% did not rate this aspect. However, $69 \%$ did not find much input from the lecturers, who claimed that the students were in-service and knew what was expected of them and that their role was to just facilitate the peer teaching process. Some respondents cited that their presentations lasted only about five minutes. They did not feel that some of the things they were learning helped them to see the bigger picture at work. $27 \%$ were satisfied with their lecturers inputs. $4 \%$ did not rate their gain on peer teaching. There has been little improvement on this aspect as a follow up engagement with respondents indicated that there are still grey areas in the conduct of peer teaching. Probably, there is need to revisit the way peer teaching is conducted so as to counter check and sharpen the abilities of all lecturers involved in peer teaching programme, including part-time lecturers - contracted specifically on peer teaching. Very serious comments were passed and this can potentially endanger the stand of the programme and the products.

\subsection{Organisational Competencies}

$75 \%$ of the respondents felt that there was a great improvements on the organisation of residential school session. They cited module distribution, registration procedures, Government receipt collection, school experience registration, both test and session lecture timetable distribution as having been improved and eased although long queues featured as the only aspect still unbearable to most respondents. 23\% still felt that lecture, peer taeching and test venues were not well organized. 
On individual and section level organisational competencies, 59\% felt that some of the sections were not well organised. Some of the displeasures cited were unexplained coure lecturers-absenteeism, lack of feedback on assignments, failure to guide students on courses taken, unavailability of section lecturers for consultations. Lack of systematic approach in ICT use in distance education settings. However, a follow up engagement with respondents on ICT challenges, $77 \%$ revealed that there was tremendious improvements in this area. They cited the installation of a fibre network to both Main and East campuses, development of student information system and putting up of access points around the two campuses. $20 \%$ were not satisfied with the ICT strides made so far while $3 \%$ did not rate this aspect.

The issue of real time feedback from lecturers or otherwise, as Swaraji Basu (2012) put it, seemed to be a common challenge in most institutions providing Distance Education. It was echoed by Zirnke (2001), Maxwell, C. et al (2015), Hara and Kling (2001) who said that students experience confusion, anxiety, and frustration due to lack of prompt or clear feedback from their lecturers. On this score, Kamau (2007) warns that without an effective learner support service system that provides on site face to face; timely feedback on student performance and access to library services, student achievement will be undermined and drop-out rates and proclastinations will increase. On personal organisational competencies, $59 \%$ felt that there was a lot room for lecturers' improvement. $38 \%$ felt that their lecturers were well organised while $62 \%$ of lecturers repondents during a follow up engagement indicated that the distance residential sessions were well organised.3\% of student respondents opted to remain mute on the issue.

With regard to factors influencing their motivation, the following issues were raised: Positive feelings of indpendence, self-reliance flowing from successful distance learning study engendered a sense of resilience, academic achievement ( These enhanced feelings of self-reliance and efficacy). For some, improved performance at work either through putting their knowledge into practice or capacity to take on greater responsibilities acted as a powerful motivator, many job opportunities awaiting their completion, and improved salary.

As for the University initaitive influencing student motivation to succeed, feelings of value for money were highlighted in terms of both quality of materials provided. Relatively low tuition fees coupled with encouraging levels of support provided by the lecturers and indeed relatively short completion period, were outlined by students.

In terms of challenges impeding their progress, the reasons advanced by students were: inadequate content coverage, 'repeat course- University exclude rule', lack of Distance Education study skills, wrong entry and missing results for end of year examination, unreliable marking by some lecturers and lack of time to do research, which Garland (2007) identified as one of the persistent challenges for students in distance learning. For instance, students felt that a two-week residential period was not enough regarding their workload and inadequate resources such as books. Lecturer respondents outlined DE students's challenges thus: students' failure to read their modules before residential and in between residential school as their time is dedicated to writing assignments which should have been written at home, students' lack of understanding what it means to study by Distance Education, and limited time allocated for residential school. Kimber (1989), however, argues that poor time management leads to challenges such as learners' ability to integrate the demand of off campus study with family, work and social commitments. Kimber's view seems to be apt to the findings in this study. Other challenges as faced by lecturers included, plagiarism by students, poor writing and research skills by students, lack of enough learning space resulting in lecture clashes, teaching huge numbers, lack of teaching and learning materials to concretise concepts, and rushing through planned work to complete it at the expense of real knowledge and skills impartation due to limited time.

\section{Conclusions}

The study suggests that great successes have been achieved in the University organisational competencies but still leaves room for improvements at section and individual levels. It is clear from the findings that lecturers should maintain a network of contacts and keeping abreast of developments taking place in the profession itself. Issues of content competencies, despite the great improvement made so far, should continue to being addressed as this can be a demotivating factor to students in left unchecked. Furthermore, this investigation suggests that not only are our student perceptions of 
distance learning changing but also that the expectations of students and lecturers are changing. However, there are still a number of challenges that stand on their path of progress. It is therefore not far fetching to conclude that student resilience and capacity to progress from one level of study to another depends partly on the institutions' ability to push out their way lecturer- caused obstacles, influence positive behaviour and putting in place Distance Education support system. The researcher recommends an improvement in the acquisition of teaching and learning materials, open up online library services for students and lecturers alike, improve module distribution, continue to motivate lecturers through financial support to their academic programmes and a wide assessement of these issues so that a generalisation can be made at higher confidence level.

\section{ACKNOWLEDGEMENTS}

The researchers wish to acknowledge all the participants in this research for their immense contribution to the success of this investiagation. Without whom the research would not have been successful. Gratude also go to Kwame Nkrumah University management for having created enabling environment for this research to be conducted. Thumbs up to fellow lecturers for their coorperation during this investigation.

\section{REFERENCES}

[1] Berge,Z.L, Muilenburg,L.Y., and Haneghan,J.V.(2002). Barriers to distance education and learning:Survey results. The Quartely Review of Distance Education, 3(4), 409-418.

[2] Carr,S. (2000). As distance education comes of age, the challenge is keeping the students. The Chronicle of higher education,46(23), 47-61.

[3] Daniel, J. (2005). Open and Distance Learning in Africa. 15CCEM Mid-Term Educational media international, 39(1), 17-22.

[4] Fozdar, B., Kumar, S.A., and Kannan, S. (2006). A Survey of study on the reasons responsble for student drop-out from the Bachelor of Science programme at Indira Gandhi National open University: IGNOU Press.

[5] Garland,M. (1993). Ethnography Penetrates the "I didn't have time" rationale to elucidate higher order reason for distance education withdrawal. Research in distance education, 8(2), 181-198.

[6] Hara,N., and Kling, R. (2003). Students' distress with a web-based distance education course: An ethnographic study of participants' experiences. Turkish online Journal of distance education, 4(2), 557-579.

[7] Kamau, J. (2007). Retraining primary school teachers against diminishing resources: Is distance education the answer? Conference paper, UNESCO, second regional serminar for Africa, Accra Ghana; UNESCO.

[8] Kember, D. (1989). A longitudinal-process model of drop-out from distance education. Journal of higher education, 60 (3), 278-301.

[9] Maxwell, C. et al . (2015). Challenges for Open and Distance learning (ODL) Students: Experiences from students of the Zimbabwe Open University. Journal of Education and Practice ISSN 2222-288X, Vol.6, No.18.

[10] Mossberger, K., Tolbert, C. and Stansbury, M. (2003). Virtual Inequality: Beyond the digital devide. Washington, D.C.: Georgetown University Press.

[11] Nsiah Agyemang, S. (2006). The Challenges Facing Distance Education Students at University of Ghana. Accra: NP.

[12] OECD. (2000). Beyond Rhetoric: Adult Learning Policies and Practices. Paris: OECD. Retrieved from www.springerlink.com/.../gp636820v09671k2.pd. on 14/07/2016

[13] Swaraj, Basu .(2012). Open and Distance Learning: Challenges and Opportunities; Interactive Discussion Programme.Indira Gandhi National Open University (IGNOU).

[14] UNESCO, (2002). Open and Distance Learning: Trends, Policy and Strategy Considerations. France: UNESCO.

[15] Zirnke, C. (2001). Access barriers in Distance Education Contemporary education, 72(2),39-42. 


\section{AUTHORS' BIOGRAPHY}

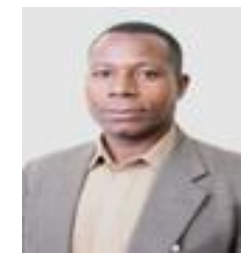

Mr. Jive Lubbungu, holds a Bachelor of Arts (BA Ed) and a Masters of Literature Degrees obtained at The University of Zambia; specialised in comparative Literature. He is currently a Lecturer at Kwame Nkrumah University, School of Humanities and Social Sciences, in the Department of Literature and Languages. He is also a $\mathrm{PhD}$ candidate in Literature at Africa Research University in Zambia. He has contributed to the advancement of knowledge through teaching, Research, administrative experience and Paper Presentations at local and at international platform. His research interest lies in comparative Literature and Contemporary Issues in relation to literary aspects.

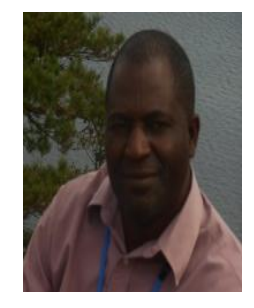

Vincent Mudenda, is a senior lecturer at Kwame Nkrumah University in the Physical Science Department.He has taught Chemistry to undergraduate students since 2007 in this Teacher Training University. Additionally, he lectures Science Education (Pedagogy). Prior to this teaching position, he taught Chemistry and Biology in four high Schools in Zambia since 1989. He holds a Masters Degree in Science Education, B.Sc Ed( Biology), Advanced Diploma in Physics, Diploma in Science: all from the University of Zambia. In addition to his role as a faculty,Vincent is active in a variety of Teacher -Continuing Professional Development activities as a mentor and at National level he participates in developing materials for Knowledge Co-creation Program (KCCP) third country training Program (TCTP) for African countries. 